\title{
Guest Editorial to the Special Issue: Lessons Learned from post-2008 Wenchuan Earthquake Community Recovery
}

\author{
Robert Olshansky ${ }^{1} \cdot \mathrm{Yu} \mathrm{Xiao}^{2} \cdot$ Daniel Abramson $^{3}$
}

Published online: 19 October 2020

(c) Springer Nature B.V. 2020

It has now been 12 years since the Wenchuan Earthquake devastated Sichuan Province, China, in May 2008. By any measure, it was one of the largest natural disasters in modern times, severely affecting an area of 50,193 square miles (130,000 square kilometers), taking over 69,000 lives (with an additional 18,000 permanently missing), and temporarily displacing 15.1 million people. It is certainly the largest natural disaster to strike modern China, comparable only to the 1976 earthquake that killed 242,000 people and destroyed Tangshan, a city of 500,000 people (Zhang et al. 2014).

The rapid physical reconstruction, completed in most places in less than 3 years, was remarkable. Several publications at the time documented this rapid reconstruction process (e.g., Yong and Booth 2011; Dunford and Li 2011) or described the recovery planning and its administration (Ge et al. 2010).

But recovery is about more than reconstructing buildings and infrastructure. Successful recovery is about rebuilding economies, communities, and lives. Over the years, researchers have studied the effects of the earthquake and subsequent recovery on households (e.g., Yang et al. 2015; Wilczak 2017; Fayazi et al. 2019), but, with a few exceptions (e.g., Abramson and Qi, 2011; Dong, 2012; Jiang 2014; Liu et al. 2014; Chandrasekhar et al. 2014; Song et al. 2017), relatively little scholarship has reflected upon the quality of community-level recovery or community planning processes. Such studies would fill an important need in the scholarship of disaster recovery, especially because of both the large scale of this disaster - the Wenchuan Earthquake significantly affected one of the nation's great economies - and because of the unique approach that China took to rapidly rebuild.

Robert Olshansky

robo@illinois.edu

Yu Xiao

yxiao@pdx.edu

Daniel Abramson

abramson@uw.edu

1 Department of Urban and Regional Planning, University of Illinois at Urbana-Champaign, 611 Taft Drive, Champaign, IL 61820, USA

2 Toulan School of Urban Studies and Planning, College of Urban \& Public Affairs, Portland State University, 506 SW Mill St, Portland, OR 97201, USA

3 Department of Urban Design and Planning, University of Washington, 410 Gould Hall, Box 355740, Seattle, WA 98195, USA 
As the 10-year anniversary of the Wenchuan Earthquake approached, we sought to identify and highlight emerging research providing critical reflections, through various lenses, on the success of community-level recovery over time. With the generous opportunity provided by Natural Hazards to publish a Special Issue, we solicited papers for the annual conference of the International Association for China Planning, held at Harbin in June 2017. The response, which consisted of 13 papers spanning three conference sessions, confirmed that numerous scholars at multiple institutions throughout China were engaged in thoughtful research that asked important questions about the characteristics, progress, and quality of the recovery since 2008 , such as: How has long-term community-scale recovery progressed, socially, economically, and physically? How was the innovative pair-assistance program implemented at the local level? How did recovery work in a range of communities, such as minority and indigenous ethnic communities? In what ways did NGOs facilitate recovery? What lessons does this recovery process provide regarding hazard mitigation, emergency management, preparedness and long-term community recovery practices?

We are now pleased to be able to present five of those papers plus three additional ones here in one volume. The first two papers, by Xiao et al. and by Tang, examine the overall administration of recovery after the 2008 earthquake. Xiao et al. review the planning, budgeting, and finance of the reconstruction, and particularly highlight the roles of pair assistance and land-based financing in paying some of the reconstruction costs. Tang demonstrates the value of taking a longer view of recovery, by describing how the initial 3 years of paired assistance provided a foundation for more deeply rooted collaborative networks that were essential to supporting ongoing recovery in the longer term.

Five of the papers provide us with glimpses into aspects of the community recovery experience at the local level. Shao et al. describe the local reconstruction processes in Weizhou and Yingxiu through the lens of resilience. In so doing, they provide insightful views into some of the local intergovernmental and political challenges regarding development and implementation of local recovery plans. Two of the contributions, by Zhang et al. and Fan et al., examine life in the famous town of New Beichuan, in which tens of thousands of earthquake-displaced inhabitants found new homes and jobs. Zhang et al., using observations and surveys, assess the social and economic life of the residents of New Beichuan. Notably, they contrast the experiences of post-disaster migrants with the indigenous peasants on whose land the new city was constructed. Fan et al. studied the evolution over time of small businesses that had restarted in New Beichuan. They document the unfortunate decline in the number of businesses, but are also able to identify several factors affecting the survival of business operations over time.

The cases of Weizhou, Yingxiu, and Beichuan are representative of urban areas affected by the earthquake, but widespread rural areas were also significantly affected. The paper by $\mathrm{Di}$ et al. examines the reconstruction and economic recovery of a rural mountain area with a strong tourism economy. Notably, the residents of Longmen Mountain Town demonstrated bottom-up adaptation to evolving post-earthquake conditions, changing their lifestyles, income sources, and construction methods to both prepare for future disasters and survive in the new post-disaster economy. Wide areas of Sichuan Province reconstructed by concentrating new homes and services into denser rural settlements closer to major transportation routes, infrastructure, and facilities such as schools and hospitals. Peng et al. evaluate the recovery success of three villages that reconstructed in this way. Given that the physical reconstruction and spatial concentration of rural settlements is the dominant form of rural development promoted by policy in China, even where no disaster requires rebuilding, this paper and others in the special issue have broad relevance beyond an assessment of the Wenchuan Earthquake recovery itself. 
Finally, Lu et al. use the example of one NGO that actively provided assistance following both the 2008 Wenchuan Earthquake and the subsequent 2013 Lushan Earthquake, showing how it evolved from a provider of resources to the leading partner in a decentralized learning ecosystem. They propose this as a potential model for future NGO disaster response in China.

We believe this volume is the most substantial collection of scholarship accessible to international scholars in English on community recovery following the Wenchuan Earthquake. That said, it is far from a complete exploration of the evolution of communities following this disaster. We look forward to seeing continued scholarship published regarding this internationally and historically significant event.

\section{References}

Abramson D, Qi Y (2011) Urban-rural integration in the earthquake zone: sichuan's post-disaster reconstruction and the expansion of the Chengdu metropole. Pac Aff 84(3):495-523

Chandrasekhar D, Zhang Y, Xiao Y (2014) Nontraditional participation in disaster recovery planning: cases from China, India, and the United States. J Am Plann Assoc 80(4):373-384. https://doi. org/10.1080/01944363.2014.989399

Dong X (2012) Post-disaster recovery planning and sustainable development: a lesson from the Wenchuan earthquake, China 2008. Masters Thesis, University of Illinois at Urbana-Champaign

Dunford M, Li L (2011) Earthquake Reconstruction in Wenchuan: assessing the state overall plan and addressing the 'forgotten phase'. Appl Geogr 31:998-1009

Fayazi M, Yeh ET, Li F (2019) Development and divergent post-disaster trajectories in a mountain village: temporal dynamics of differentiation after the 2008 Wenchuan earthquake. World Dev 124:10466. https://doi.org/10.1016/j.worlddev.2019.104663

Ge Y, Gu Y, Deng W (2010) Evaluating China's National post-disaster plans: the 2008 Wenchuan earthquake's recovery and reconstruction planning. Int J Disaster Risk Sci 1(2):17-27

Jiang W (2014) Towns undergoing changes: a case study on the recovery after the Wenchuan earthquake, China. Masters Thesis, University of Illinois at Urbana-Champaign

Liu L, Lin Y, Wang S (2014) Urban design for post-earthquake reconstruction: a case study of Wenchuan County, China. Habitat Int 41:290-299. https://doi.org/10.1016/j.habitatint.2013.09.001

Song Y, Li C, Olshansky R, Zhang Y, Xiao Y (2017) Are we planning for sustainable disaster recovery? Evaluating recovery plans after the Wenchuan earthquake. J Environ Plan Manag 60(1):1-25. https:// doi.org/10.1080/09640568.2017.1282346

Wilczak J (2017) Reconstructing Rural Chengdu: urbanization as development in the post-quake context. Ph.D. Dissertation, University of Toronto. http://hdl.handle.net/1807/99022

Yang S, Du J, He S et al (2015) The emerging vulnerable population of the urbanisation resulting from postdisaster recovery of the Wenchuan earthquake. Nat Hazards 75:2103-2118. https://doi.org/10.1007/ s11069-014-1413-z

Yong C, Booth DC (2011) The Wenchuan earthquake of 2008: anatomy of a disaster. Science Press and Springer, Beijing and Berlin

Zhang Y, Zhang C, Drake W, Olshansky R (2014) Planning and recovery following the great 1976 Tangshan earthquake. J Plann Hist 14(3):224-243. https://doi.org/10.1177/1538513214549435

Publisher's Note Springer Nature remains neutral with regard to jurisdictional claims in published maps and institutional affiliations. 